\title{
The Structure of the Covalent Flavin Adduct Formed between Lactate Oxidase and the Suicide Substrate 2-Hydroxy-3-butynoate ${ }^{\dagger}$
}

\author{
A. Schonbrunn, R. H. Abeles, ${ }^{*}$ C. T. Walsh, S. Ghisla, ${ }^{\ddagger}$ H. Ogata, and V. Massey
}

ABSTRACT: 2-Hydroxy-3-butynoic acid is a suicide substrate for Mycobacterium smegmatis lactate oxidase. Inactivation occurs by covalent modification of enzyme-bound FMN and does not involve labeling of the apoprotein. The spectrum of the enzyme bound adduct suggests that it is a 4a,5-dihydroflavin derivative. When this adduct is released from the enzyme, a complex mixture of unstable compounds is obtained. When the initially formed enzyme-bound adduct is reduced with

L -lactate oxidase (EC 1.13.12.4) from Mycobacterium smegmatis catalyzes the oxidative decarboxylation of L-lactate.

$$
\mathrm{H}_{3} \mathrm{CCHCOO}^{-}+\mathrm{O}_{2} \rightarrow \mathrm{H}_{3} \mathrm{CCOO}^{-}+\mathrm{H}_{2} \mathrm{O}+\mathrm{CO}_{2}
$$

The substrate analogue DL-2-hydroxy-3-butynoate (I) acts as both a substrate (i.e., is oxidatively decarboxylated) and an irreversible inactivator of the enzyme (Walsh et al., 1972a).<smiles>C#CC(O)C(=O)[O-]</smiles>

Evidence has been presented that 2-hydroxy-3-butynoate is bound at the same binding site for both the inactivation and oxidation reactions (Ghisla et al., 1976). Which of the two processes occurs is determined by the concentration of the second substrate, oxygen (Walsh et al., 1972a; Ghisla et al., 1976). The lower the concentration of oxygen, the fewer turnovers the enzyme undergoes before it is inactivated. Under anaerobic conditions $1 \mathrm{~mol}$ of L-2-hydroxy-3-butynoate per mol of flavin containing active site causes complete inactivation (Walsh et al., 1972a). Both the $\alpha$-hydroxyl group and the $\beta$ acetylenic linkage of 2-hydroxy-3-butynoic acid are necessary for inactivation to occur since neither 3-butynoic acid nor vinylglycolic acid inactivate the enzyme (Walsh et al., 1972a).

Inactivation of lactate oxidase with 2-hydroxy-3-butynoate

\footnotetext{
† From the Graduate Department of Biochemistry (Publication No. 1074), Brandeis University (A.S. and R.H.A.), Waltham, Massachusetts 02154. the Department of Chemistry, Massachusetts Institute of Technology (C.T.W.), Cambridge, Massachusetts 02139, and the Department of Biological Chemistry, The University of Michigan (S.G., H.O., and V.M.), Ann Arbor, Michigan 48104. Received December 2, 1975. This research was supported in part by grants from the National Science Foundation (GB 31952) to R.H.A., National Institutes of Health Training Grant (5T01GM00212) to A.S., L.S. Public Health Service (GM 11106 ) to V.M., and the National Science Foundation (GU 3852 and GP 37156) to A. G. Redfield.

$\$$ Present address: Department of Biological Chemistry, Yamaguchi University, Ube, Japan

$\ddagger$ Present address: Fachbereich Biologie, University of Konstanz, West
} Germany.

$\mathrm{NaBH}_{4}$, a major stable species can be resolved from the enzyme and can be isolated and purified. The structure was established by appropriate isotope substitutions, Fourier transform NMR spectroscopy, chemical reactivity, and synthesis of a model compound. The structure of the isolated adduct is structure II, Scheme II. The structure proposed for the adduct initially formed on the enzyme is structure VII, Scheme II.

results in covalent modification of the flavin coenzyme but does not affect the apoprotein (Walsh et al., 1972a). The enzymebound flavin-2-hydroxy-3-butynoate adduct displays absorption peaks with maxima at 320 and $368 \mathrm{~nm}$ characteristic of 4a-mono- or 4a,5-disubstituted 4a,5-dihydroflavin derivatives (Ghisla et al,, 1973; Ghisla et al., 1974). Previously reported experinents with DL-2-hydroxy-3-butynoate labeled with tritium at $C_{2}$ and $C_{4}$ have indicated that the $C_{2}$ hydrogen of 2-hydroxy-3-butynoate is not present in the flavin adduct, while the $\mathrm{C}_{4}$ hydrogen is present, but no longer in an acetylenic linkage (Walsh et al., 1972a)

As shown in the preceding paper (Ghisla et al., 1976) the modified flavin of the inactivated enzyme is reduced by borohydride. Such reactivity, as well as the spectroscopic properties, suggested strongly that the flavin derivative formed on reaction of lactate oxidase with 2-hydroxy-3-butynoate is a cyclic adduct involving substitution both at the $\mathrm{N}(5)$ and $\mathrm{C}(4 \mathrm{a})$ positions of the flavin. In this paper we report experiments which establish the structure of the flavin-2-hydroxy-3butynoate adduct.'

Materials and Methods

\section{Materials}

Lactate oxidase (EC 1.13.12.4) was purified to homogeneity (specific activity, 40-60 units/mg) from Mycobacterium smegmatis essentially according to the method of Sullivan (1968) with the modification that the bacteria were broken by sonication for 15 min at full power with a Branson Model J17V sonifier with a standard $3 / 4$-in. tip and then treated for $1 \mathrm{~h}$ at $4^{\circ} \mathrm{C}$ with $20 \mathrm{mg}$ of pancreatic DNase per l. to reduce viscosity. Aspergillus niger glucose oxidase type $\mathrm{V}$ (specific activity, 1250 units $/ \mathrm{ml})$ was purchased from Sigma. $\left[{ }^{3} \mathrm{H}\right] \mathrm{H}_{2} \mathrm{O}(1 \mathrm{C} / \mathrm{g})$ and sodium $\left[{ }^{3} \mathrm{H}\right]$ borohydride $(138 \mathrm{mCi} / \mathrm{mmol})$ were purchased from New England Nuclear. Sodium borodeuteride was purchased from Merck, Sharp and Dohme. $\mathrm{D}_{2} \mathrm{O}(99.86 \%)$ was purchased from Bio-Rad Laboratories. $\mathrm{D}_{2} \mathrm{O}(99.98 \%)$ was purchased from Stohler Isotope Chemicals.

DL-2-Hydroxy-3-butynoate was prepared by published

1 A preliminary report on this work has been published (Schonbrunn al. 1976). 
procedures (Verny and Vessiere, 1967; Leonard, 1956). DL2-Hydroxy-3- $\left[4-{ }^{3} \mathrm{H}\right]$ butynoate was prepared by equilibration of the acid with $\left[{ }^{3} \mathrm{H}\right] \mathrm{H}_{2} \mathrm{O}$ at $\mathrm{pH} 10$ for $30 \mathrm{~min}$ and purified by silicic acid chromatography according to J. E. Varner (Varner, $1957)$ with $10 \%(\mathrm{v} / \mathrm{v}) n-\mathrm{BuOH}$ in chloroform as the eluent. DL-2-Hydroxy-3-[4- $\left.{ }^{2} \mathrm{H}\right]$ butynoate was prepared in an analogous manner by equilibration with $\left[{ }^{2} \mathrm{H}\right] \mathrm{H}_{2} \mathrm{O}$. Nuclear magnetic resonance spectroscopy indicated no detectable $\gamma$ proton, nor any chemical impurity. DL-2-Hydroxy-3-[1${ }^{14} \mathrm{C}$ ]butynoate $(35 \mathrm{mCi} / \mathrm{mmol})$ was a gift from $\mathrm{Dr}$. A. Lieberman of Hoffmann-La Roche, Inc. $\left[2-{ }^{14} \mathrm{C}\right]$ Riboflavin was purchased from Amersham, phosphorylated enzymatically with partially purified rat liver flavokinase (McCormick, 1971) and then purified on a Bio-Gel P2 column by elution with distilled water to yield 2-[ $\left.{ }^{14} \mathrm{C}\right] \mathrm{FMN}$. 5,7,8-Trimethylpyrroloquinoxalinium iodide was synthesized by the procedure of Cheeseman and Tuck (1966; decomposition point, 275-277 ${ }^{\circ} \mathrm{C}$; see Results for NMR data).

Precoated silica gel TLC plates, containing no fluorescent indicator, were purchased from Eastman. Silica gel G (type 60 ) used to coat $20 \times 20 \mathrm{~cm}$ glass plates for thin-layer electrophoresis was purchased from Brinkman Inc. All other materials were readily available commercial products.

\section{Methods}

Lactate oxidase was assayed by L-lactate-dependent oxygen consumption with an oxygen electrode Model 1-2001 purchased from William E. Lauer, Baltimore, Md. Assays were carried out in $100 \mathrm{mM}$ L-lactate, $50 \mathrm{mM}$ imidazole chloride, $\mathrm{pH} 7$. Activity is expressed as $\mu \mathrm{mol}$ of $\mathrm{O}_{2}$ consumed per min, calculated on the assumption that the concentration of oxygen in solutions at room temperature is $0.24 \mathrm{mM}$.

The protein concentration of crude enzyme solutions was estimated using the method of Lowry with crystalline bovine serum albumin as a standard (Lowry et al., 1951). Lactate oxidase concentration was determined from the reported extinction coefficient of enzyme bound FMN at $452 \mathrm{~nm}$ (Sullivan, 1968).

Radioactivity was determined with a Packard TriCarb liquid scintillation counter. Chromatograms were scanned for radioactivity with a Tracerlab $4 \pi$ Scanner.

Optical spectra were recorded with a Cary 14 or Cary 18 recording spectrophotometer. Fluorescence and excitation spectra were recorded with a Perkin-Elmer fluorescence spectrophotometer Model MPF-3.

Proton magnetic resonance spectra were recorded with a Bruker WH 90 Fourier transform NMR spectrometer at a sweep width of $1200 \mathrm{~Hz}$ or with a Bruker WH 90 modified to suppress the water signal as previously described (Redfield and Gupta, 1971) at a sweep width of $1000 \mathrm{~Hz}$. Samples were prepared for NMR by repeated lyophilization from $99.8 \% \mathrm{D}_{2} \mathrm{O}$ to remove as much $\mathrm{H}_{2} \mathrm{O}$ as possible. Spectra were run on $0.3-\mathrm{ml}$ samples in $99.98 \% \mathrm{D}_{2} \mathrm{O}$ at room temperature. Chemical shifts were measured in parts per million using the absorption peak of the solvent as an internal standard (HDO, $4.75 \mathrm{ppm}$ ).

Inactivation of Lactate Oxidase. Anaerobic inactivation reactions were carried out in a sealed, two-compartment reaction vessel. One to five milliliters of a $1-7 \mathrm{mg} / \mathrm{ml}$ solution of lactate oxidase in buffer containing $0.1 \mathrm{M}$ glucose was placed in the main compartment and 10-20 $\mu$ lof DL-2-hydroxy-3-butynoate in water was placed in the side compartment. The vessel was deaerated and flushed with argon for five cycles and left under positive argon pressure. Approximately $25 \mu \mathrm{l}$ of glucose oxidase was then injected into the main compartment and incubated at room temperature for $15 \mathrm{~min}$. The solutions in the two compartments were then mixed and inactivation was allowed to proceed at room temperature. Aliquots were withdrawn with a Hamilton syringe and assayed to monitor the rate of inactivation. When inactivation was greater than $95 \%$ complete (5-50 min depending on the concentration of inactivator), a large excess of $\mathrm{NaBH}_{4}(5-10 \mathrm{mg}$ ) dissolved in approximately $0.2 \mathrm{ml}$ of water was injected and allowed to react for about $30 \mathrm{~min}$ at room temperature. The $\mathrm{pH}$ after $\mathrm{NaBH}_{4}$ reduction was never above $\mathrm{pH} 8$. Unreacted borohydride was removed by reaction with excess sodium pyruvate. When the evolution of $\mathrm{H}_{2}$ gas ceased (about $30 \mathrm{~min}$ ), the reaction mixture was applied to a Sephadex G25 column and eluted with distilled water at room temperature. The entire procedure was carried out without direct overhead lighting.

Protein containing fractions from Sephadex G25 chromatography were pooled and 4 volumes of methanol was added to denature the enzyme. After precipitation overnight at $4{ }^{\circ} \mathrm{C}$, the sample was centrifuged and the supernatant was concentrated by rotary evaporation.

Aerobic inactivation of lactate oxidase required a sufficient excess of 2-hydroxy-3-butynoate to ensure complete inactivation before the 2-hydroxy-3-butynoate is completely oxidized by the enzyme. The same adduct species were formed, whether inactivation was carried out under aerobic or anaerobic conditions.

Thin-Layer Chromatography of the Adduct. Samples were spotted on Eastman silica gel TLC plates without fluorescent indicator and developed for $8 \mathrm{~h}$ with 1-butanol-ethanol-0.01 $\mathrm{M}$ sodium acetate, $\mathrm{pH} 5.4$ (1:1:1). Spots were visualized by their fluorescence under a uv mineralight. Radioactivity was determined either by scanning with a Tracerlab $4 \pi$ Scanner or by cutting the chromatogram into $1 / 2-\mathrm{cm}$ strips and counting in a liquid scintillation counter.

Thin-Layer Electrophoresis. Samples were spotted $6 \mathrm{~cm}$ from one edge of a $20 \times 20 \mathrm{~cm}$ glass plate coated with a $2-\mathrm{mm}$ thick layer of silica gel G. Electrophoresis was carried out at $400 \mathrm{~V}$ for $8 \mathrm{~h}$ in $0.02 \mathrm{M} \mathrm{Na}^{+} \mathrm{PO}_{4}{ }^{-3}$ buffer, $\mathrm{pH} 7$, with the cathode connected to the edge of the plate nearest the sample. Flavin adduct species were visualized by their fluorescence under a uv mineralight. Radioactivity was determined by liquid scintillation counting of the material eluted from the silica gel with distilled water. The major adduct species migrated toward the positive electrode. Binder eluted from Eastman silica gel TLC plates was visualized by $\mathrm{I}_{2}$ and remained at the origin.

Preparation of Apolactate Oxidase and Reconstitution with $2-\left[{ }^{14} \mathrm{C}\right] F M N$. Lactate oxidase $(3-10 \mathrm{mg} / \mathrm{ml})$ was resolved into apoenzyme and coenzyme components according to the procedure of Choong et al. (1975). The apoenzyme retained less than $0.1 \%$ of the initial activity. Incubation of the apoenzyme in $0.1 \mathrm{M}$ Tris-acetate buffer, $\mathrm{pH} \mathrm{7.8,} \mathrm{with} \mathrm{an} \mathrm{excess} \mathrm{of} \mathrm{2-}$ $\left[{ }^{14} \mathrm{C}\right] \mathrm{FMN}$ for $1 \mathrm{~h}$ at room temperature followed by overnight dialysis against $0.1 \mathrm{M}$ sodium acetate, $\mathrm{pH} 5.7$, at $4{ }^{\circ} \mathrm{C}$ resulted in restoration of holoenzyme. Denatured apoprotein, not reconstituted with $\left[{ }^{14} \mathrm{C}\right] \mathrm{FMN}$, was removed by centrifugation. Recovery of protein was generally about $75 \%$, and of this $70-100 \%$ was converted to holoenzyme, as determined by amount of $\left[{ }^{14} \mathrm{C}\right] \mathrm{FMN}$ bound.

\section{Results}

Components of 2-Hydroxy-3-butynoate Retained in the Flavin Adduct. The flavin-2-hydroxy-3-butynoate adduct contains the $\mathrm{C} 4$ hydrogen of 2-hydroxy-3-butynoate, but not the C2 hydrogen (Walsh et al. 1972a). To establish whether the flavin-inhibitor adduct contains the carboxyl group of the inactivator, homogeneous lactate oxidase $(2.9 \mathrm{mg})$ was inac- 


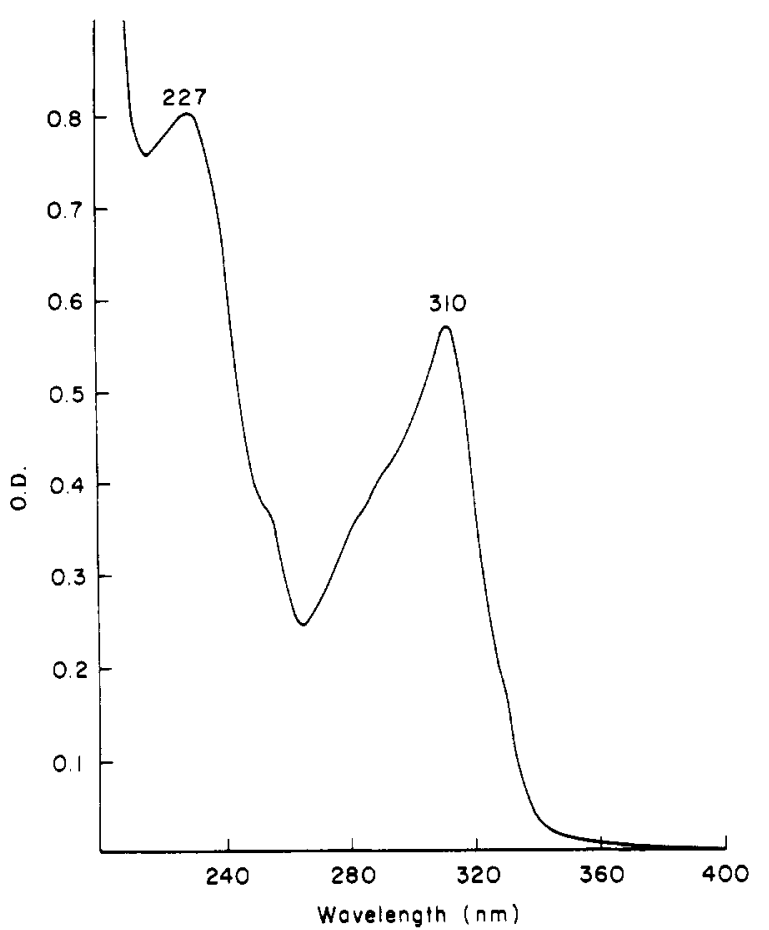

FIGURE 1: Lactate oxidase ( $1.04 \mathrm{mg}$; specific activity, 51.6$)$ in $1.1 \mathrm{ml}$ of $0.05 \mathrm{M}$ imidazole chloride $\mathrm{pH} 7$, was incubated aerobically with $10.5 \mu \mathrm{mo}$ of DL-2-hydroxy-3-butynoate for $25 \mathrm{~min}$. After precipitation of the protein with methanol and concentration of the supernatant, the sample was applied to a Bio-Gel P2 column $(1.5 \times 90 \mathrm{~cm})$ and eluted with distilled water. The spectrum of the second peak eluted is shown.

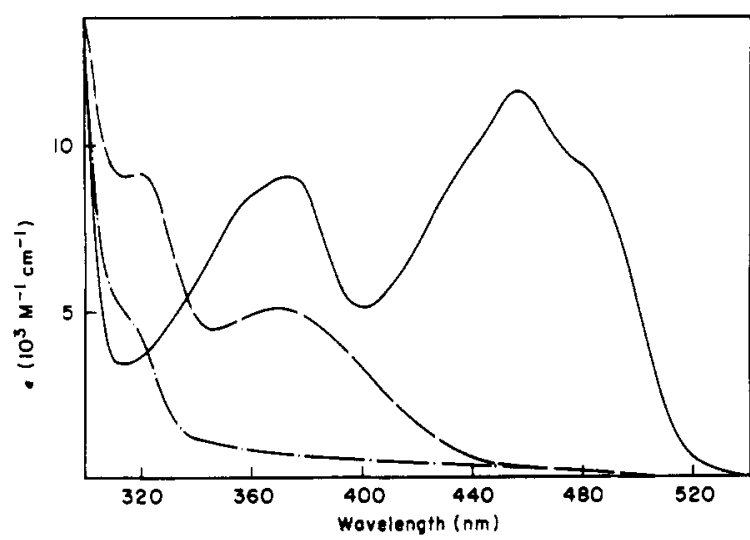

FIGURE 2: Spectral changes observed on aerobic inactivation of lactate oxidase with 2-hydroxy-3-butynoate and $\mathrm{NaBH}_{4}$ reduction of inactivated enzyme. (-) Spectrum of $1.44 \mathrm{mg}$ of lactate oxidase in $0.8 \mathrm{ml}$ of $0.01 \mathrm{M}$ sodium acetate, $\mathrm{pH} 8 .(\ldots)$ Spectrum $15 \mathrm{~min}$ after the addition of $50 \mu \mathrm{l}$ $(1.23 \mu \mathrm{mol})$ of DL-2-hydroxy-3-butynoate. The enzyme is catalytically inactive at this point. (....) Spectrum 30 min after the addition of a few milligrams of solid $\mathrm{NaBH}_{4}$ to the inactivated enzyme. Excess borohydride was destroyed by reaction with $50 \mu$ lof acetone for $5 \mathrm{~min}$.

tivated with 3.4-fold molar excess of DL-2-hydroxy-3-[1${ }_{14}^{4} \mathrm{C}$ ] butynoate (specific activity, $35 \mathrm{mCi} / \mathrm{mmol}$ ) under anaerobic conditions in $0.01 \mathrm{M}$ sodium acetate buffer, $\mathrm{pH} 5.4$. At the end of $5 \mathrm{~min}$, at which time $93 \%$ of the enzyme activity was lost, the reaction mixture was placed on a $1.6 \times 30 \mathrm{~cm}$ Sephadex G25 column and eluted with distilled water. The protein peak contained $94 \%$ of the ${ }^{14} \mathrm{C}$ radioactivity expected, assuming that $1 \mathrm{~mol}$ of inactivator is bound per mol of flavin containing active site. Thus, inactivation of the enzyme must occur without decarboxylation (loss of carbon 1). Addition of 4 volumes of methanol to inactivated holoenzyme eluted from the Sephadex column caused precipitation of the apoprotein

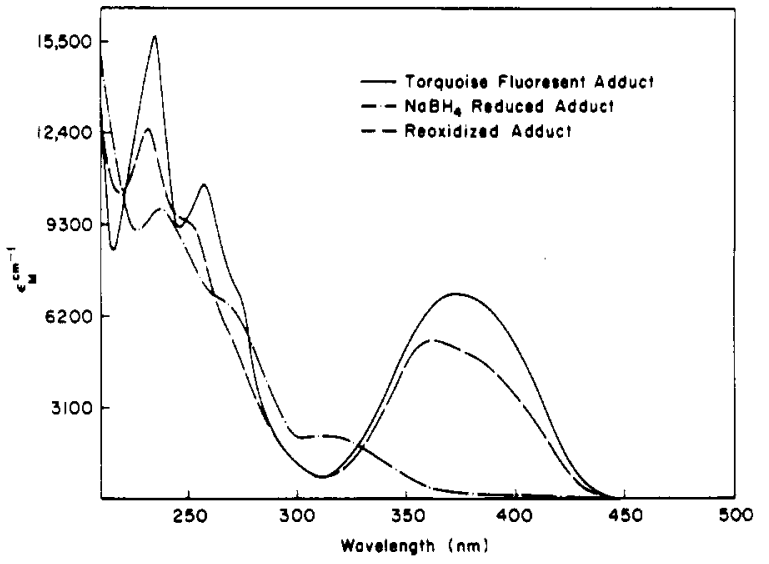

FIGURE 3: Spectrum of borohydride reduced adduct after removal from the apoprotein. (-) Spectrum of the major adduct eluted from a thin-layer chromatogram of the species released from borohydride reduced, inactivated lactate oxidase. (....) Spectrum of the adduct 5 min after the addition of a 300 -fold excess of $\mathrm{NaBH}_{4}$. (-) Spectrum after reoxidation had been allowed to occur for $88 \mathrm{~h}$ at room temperature in the dark.

and quantitative release of the ${ }^{14} \mathrm{C}$-labeled flavin-inhibitor adduct. Less than $2 \%$ of the ${ }^{14} \mathrm{C}$ originally incorporated remains associated with the apoprotein.

Isolation of the Flavin-Inactivator Adduct. The initial adduct formed on the enzyme was found to be unstable and to undergo slow spectroscopically detectable changes. At $\mathrm{pH} 7$, $25^{\circ} \mathrm{C}$, the near-ultraviolet absorption of the modified enzyme decreases by $50 \%$ over a period of $24 \mathrm{~h}$ and finally results in a rather featureless absorption spectrum characterized by shoulders at 320 and $370 \mathrm{~nm}$. Concomitantly, the fluorescence emission intensity decreases to $20 \%$ of the original value, although the emission maximum remains unchanged (Ghisla et al., 1976).

When inactivated enzyme is denatured with methanol, the released modified flavin consists of a mixture of compounds. The composition of the products obtained, as judged by absorption and fluorescence spectra and thin-layer chromatography of the components, depended on whether the flavin was released immediately after inactivation or after the slow spectral changes described above had occurred. When the flavin-inhibitor adduct released by methanol was chromatographed on Bio-Gel P2 by elution with distilled water, several distinct peaks were eluted. The spectrum of one of these species (Figure 1) is very similar to the spectrum of one of the decomposition products (compound C, Scheme III) obtained from a 4a,5-dihydroflavin derivative (compound A, Scheme III) formed photochemically from $N, N$-dimethylpropargylamine and 3-methyllumiflavin (Zeller et al., 1972; Gartner, 1974). However, since the adduct eluted from Bio-Gel P2 was obtained in variable yields depending on how rapidly after inactivation the modified flavin was released from the enzyme, the nature of this species was not investigated further. Therefore, alternate methods were explored which would allow the reproducible isolation of a major stable adduct species.

In the accompanying manuscript, it was demonstrated that the adduct initially formed on the enzyme can be reduced with $\mathrm{NaBH}_{4}$ (Ghisla et al., 1976). We investigated this reduced adduct further to establish whether it yielded a more stable compound suitable for further structural studies. The spectral changes observed on sodium borohydride reduction of inactivated lactate oxidase are shown in Figure 2. A typical spectrum of this adduct after release from the apoprotein is shown in Figure 3. The spectrum of the borohydride reduced adduct released into solution differs from its spectrum while enzyme 
Table I: Inactivation of Lactate Oxidase with

2-Hydroxy-3- $\left[4-{ }^{3} \mathrm{H} ; 1-1{ }^{14} \mathrm{C}\right]$ butynoate. ${ }^{a}$

\begin{tabular}{lc}
\hline & ${ }^{14} \mathrm{C} /{ }^{3} \mathrm{H}$ \\
\hline 2-Hydroxy-3-[4- $\left.{ }^{3} \mathrm{H} ; 1-{ }^{14} \mathrm{C}\right]$ butynoate & 0.88 \\
Protein off Sephadex G25 & 0.97 \\
Concd adduct released from protein & 0.92 \\
Turquoise fluorescent adduct after TLC & 0.72 \\
Turquoise fluorescent adduct after TLE & 0.93 \\
\hline
\end{tabular}

$a$ Seven milligrams of lactate oxidase (specific activity, $8 \mu \mathrm{mol} /$ ( $\mathrm{min} \mathrm{mg}^{-1}$ )) in $1 \mathrm{ml}$ of $0.02 \mathrm{M} \mathrm{Tris-Cl}, \mathrm{pH} 8$, was incubated anaerobically with $7.2 \mu \mathrm{mol}$ of DL-2-hydroxy-3- $\left[4-{ }^{3} \mathrm{H} ; 1-{ }^{14} \mathrm{C}\right]$ butynoate $\left({ }^{3} \mathrm{H}\right.$ specific activity, $3.75 \times 10^{5} \mathrm{dpm} / \mu \mathrm{mol} ;{ }^{14} \mathrm{C}$ specific activity, $3.32 \times 10^{5} \mathrm{dpm} / \mu \mathrm{mol}$ ) for $30 \mathrm{~min}$. The $\mathrm{NaBH}_{4}$ reduced holoenzyme contained $0.98 \mathrm{~mol}$ of 2 -hydroxy-3- $\left[4-{ }^{3} \mathrm{H} ; 1-{ }^{-4} \mathrm{C}\right]$ butynoate per mol of tlavin containing active site after gel permeation chromatography. Ninety percent of the counts associated with the protein peak were present after precipitation of the protein and concentration of the supernatant. After thin-layer chromatography on silica gel, $43 \%$ of the total radioactivity spotted was recovered by elution of the major turquoise fluorescent spot with distilled water. After electrophoresis on silica gel, $30 \%$ of the radioactivity spotted was recovered by elution of the major turquoise fluorescent spot by distilled water. The overall recovery of adduct was $12 \%$.

bound (compare Figures 2 and 3). Most notably, a sevenfold increase in the absorbance at $370 \mathrm{~nm}$ has occurred. Furthermore, while the enzyme bound, borohydride reduced adduct is nonfluorescent, the released adduct is strongly fluorescent with a maximum emission at $465 \mathrm{~nm}$. When the $\mathrm{pH}$ is lowered from 7 to $\sim 0$, a minor red shift of the $370 \mathrm{~nm}$ band occurs and a rather large increase in the $250-280 \mathrm{~nm}$ region reflecting a $\mathrm{p} K$ of 1.4. This indicates that the change in ionization does not affect the chromophore directly but is probably associated with a substituent. In marked contrast to this, at high $\mathrm{pH}$ ( $\mathrm{pK}=$ 11.0 ), a drastic and reversible change in the absorption occurs, which is accompanied by disappearance of the blue fluorescence emission. This suggests that addition of $\mathrm{R}-\mathrm{O}^{-}$occurs to the chromophore and implies the presence of a strongly electron-deficient system. The properties of the new chromophore $\left(\lambda_{\max } 305 \mathrm{~nm}\right)$ are characteristic of phenylenediamines (Ghisla et al., 1976; Zeller et al., 1972). The fact that the spectral properties of the released adduct differ from those of enzyme bound adduct show that a structural modification of the coenzyme complex has occurred after release from the apoprotein.

The reduced adduct is stable since no further spectral changes occur over a period of several months. Thin-layer chromatography (see below) shows that the released flavininhibitor adduct consists of one major component. The reduced adduct was used for all further structural studies.

Characterization of the Borohydride Stabilized Adduct. In order to further characterize the nature of the borohydride reduced adduct, lactate oxidase was inactivated anaerobically with a 50 -fold excess of DL-2-hydroxy-3-[1-14 C; $\left.4-{ }^{3} \mathrm{H}\right]$ butynoate, reacted with excess $\mathrm{NaBH}_{4}$ and the reduced flavininhibitor adduct was released from the enzyme and purified. The ${ }^{14} \mathrm{C} /{ }^{3} \mathrm{H}$ ratio on the adduct was determined at various stages during the purification procedure and is shown in Table I. The ${ }^{14} \mathrm{C} /{ }^{3} \mathrm{H}$ ratio remains essentially unchanged throughout the isolation procedure. Thus, both the $\gamma$ hydrogen and carboxyl carbon of the inactivator are still present in the isolated purified turquoise fluorescent species in the same ratio as in the original adduct formed on the enzyme.

Scanning of a thin-layer chromatogram of the methanol released adduct species showed that greater than $90 \%$ of the

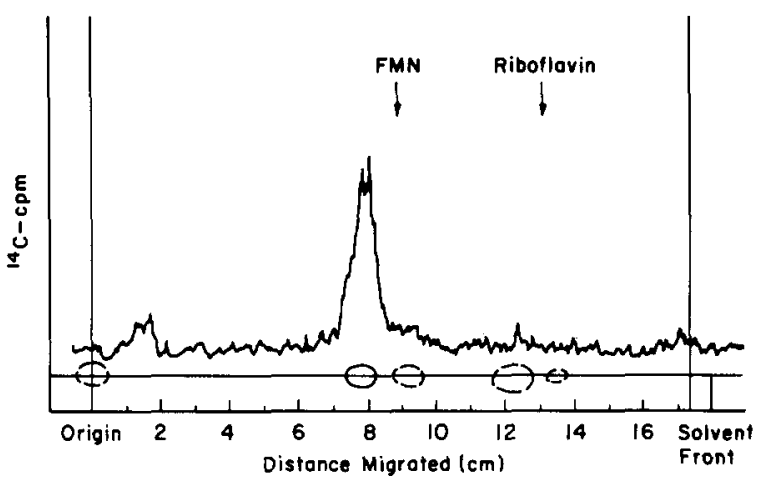

FIGURE 4: Thin-layer chromatogram of the adduct species released from inactivated, borohydride reduced lactate oxidase. Thin-layer chromatogram of the methanol released adduct of the experiment described in Table 1. Spots were visualized with a mineralight under uv at $254 \mathrm{~nm}$ and the chromatogram was scanned for radioactivity with a Tracerlab $4 \pi$ scanner. The position at which FMN and riboflavin migrate is shown for comparison.

radioactivity was located in a single peak (Figure 4). Although several minor fluorescent species were observed on the chromatogram, the most intensely fluorescent spot, which fluoresced a bright turquoise, coincided with the radioactive peak. Therefore, the adduct isolated after borohydride reduction represents one major species. When this turquoise fluorescent spot was eluted from the thin-layer chromatogram with distilled water, recovery of $370 \mathrm{~nm}$ absorbing material was proportional to recovery of radioactivity. Approximately $43 \%$ of the amount spotted was recovered with elution. The eluted material has the absorption spectrum shown in Figure 3 and an intense fluorescence spectrum with an emission maximum at $465 \mathrm{~nm}$. Thus, a major adduct derived from the original enzyme-bound flavin-2-hydroxy-3-butynoate adduct, containing the $\gamma$ hydrogen and the carboxyl carbon of the inactivator, can be isolated.

This adduct was further purified by thin-layer electrophoresis on silica gel $\mathrm{G}$ to separate the adduct from the binder also eluted from commercial silica gel thin-layer chromatography plates. This step was found necessary in the NMR experiments described below since binder interfered in the areas of interest in the NMR spectrum of the adduct. The turquoise fluorescent spot contained more than $70 \%$ of the total radioactivity on the electrophoresis plate.

When the purified turquoise fluorescent adduct was rechromatographed on silica gel plates, it always gave a single spot and was stable to storage at $4^{\circ} \mathrm{C}$ protected from light for several months. Thus, this procedure was adopted in all subsequent experiments for the preparation and purification of the major stabilized adduct species released from inactivated lactate oxidase. The overall yield obtained varied between 10 and $20 \%$ of the adduct originally formed on the enzyme. Since adduct preparations were generally carried out with small amounts of material ( $0.1-3 \mu \mathrm{mol}$ of starting enzyme), losses were attributed mainly to incomplete elution from silica gel after chromatography and electrophoresis and to sticking to glass surfaces during the workup.

Further radioisotope experiments were performed to determine (a) whether hydrogen from borohydride is incorporated into the purified stabilized adduct, (b) whether hydrogen from water is incorporated, and (c) whether the pyrimidine nucleus of the flavin ring remains intact.

Lactate oxidase $(1.4 \mathrm{mg}$ ) in $0.8 \mathrm{ml}$ of $0.01 \mathrm{M}$ sodium acetate buffer, $\mathrm{pH} 8.1$, was incubated aerobically with an excess of DL-2-hydroxy-3-butynoate and the inactivated enzyme was 
Table II: Inactivation of Lactate Oxidase with

2-Hydroxy-3-[1- $\left.{ }^{14} \mathrm{C}\right]$ butynoate in ${ }^{3} \mathrm{H}_{2} \mathrm{O} \cdot{ }^{a}$

\begin{tabular}{lcc} 
& & $\begin{array}{l}\text { mol of }{ }^{3} \mathrm{H} / \\
\text { mol of }{ }^{14} \mathrm{C}\end{array}$ \\
\hline $\begin{array}{l}\text { SA of } 2 \text {-hydroxy- }\left[1-{ }^{14} \mathrm{C}\right] \text { butynoate } \\
\text { SA of }{ }^{3} \mathrm{H}_{2} \mathrm{O}\end{array}$ & 0.12 & \\
Protein off Sephadex G 25 & 0.002 & 68 \\
Concd adduct released from protein & 0.01 & 12 \\
Turquoise fluorescent adduct after TLC & 0.29 & 0.4 \\
Turquoise fluorescent adduct after TLE & 0.20 & 0.6
\end{tabular}

$a$ Lactate oxidase (1.4 mg; specitic activity (SA), $8 \mu \mathrm{mol} /(\mathrm{min}$ $\left.\mathrm{mg}^{-1}\right)$ ) in $0.04 \mathrm{M}$ Tris-Cl buffer, $\mathrm{pH} 8$, in ${ }^{3} \mathrm{H}_{2} \mathrm{O}\left(\mathrm{SA}, 8.1 \times 10^{6} \mathrm{dpm} /\right.$ $\mu \mathrm{mol}$ ) was incubated anaerobically with $5.2 \mu \mathrm{mol}$ of DL-2-hydroxy$3-\left[1-{ }^{14} \mathrm{C}\right]$ butynoate $\left(\mathrm{SA}, 9.4 \times 10^{5} \mathrm{dpm} / \mu \mathrm{mol}\right)$ for $30 \mathrm{~min}$ and then reduced with $\mathrm{NaBH}_{4}$ for $30 \mathrm{~min}$. The adduct was purified by the procedure given in Methods.

reduced with $\left[{ }^{3} \mathrm{H}\right] \mathrm{NaBH}_{4}$ (specific activity, $138 \mathrm{mCi} / \mathrm{mmol}$ ). The protein, purified on a Sephadex G25 column, was radioactively labeled. When the protein was precipitated with methanol, all the tritium associated with the enzyme was in the supernatant. The tritium released $(93 \%)$ into solution adsorbed to charcoal. Therefore, the radioactivity must be associated with the coenzyme derived adduct. Additionally, when the adduct species released by methanol were subjected to thin-layer chromatography, the turquoise fluorescent spot was again by far the most intense and was found to contain more than $70 \%$ of the tritium label. This experiment, therefore, shows that hydrogen from sodium borohydride is incorporated into the isolated adduct. ${ }^{2}$

Table II shows the results of an experiment in which lactate oxidase was inactivated with 2 -hydroxy-3-[1-14 $\mathrm{C}]$ butynoate in ${ }^{3} \mathrm{H}_{2} \mathrm{O}$. The protein peak after Sephadex $\mathrm{G} 25$ chromatography contained a large molar excess of tritium presumably bound to the apoprotein. The amount of tritium present decreased considerably after release of the adduct by methanol and centrifugation of the denatured protein. The adduct purified by thin-layer chromatography and electrophoresis contained about $0.5 \mathrm{~mol}$ of tritium per mol of ${ }^{14} \mathrm{C}$-labeled adduct. The incorporation of less than $1 \mathrm{~mol}$ of tritium from ${ }^{3} \mathrm{H}_{2} \mathrm{O}$ per mol of 2 -hydroxy-3-[ $\left[1-{ }^{14} \mathrm{C}\right]$ butynoate is probably due to a tritium selection. ${ }^{2}$ Therefore, at least one nonexchangeable proton is incorporated into the adduct from water.

To determine whether the intact isoalloxazine nucleus was still present in the adduct, an experiment with ${ }^{14} \mathrm{C}$ coenzyme, labeled in the $\mathrm{C} 2$ position, and ${ }^{3} \mathrm{H}$-labeled inactivator was carried out. Lactate oxidase ( $1.3 \mu \mathrm{mol}$; specific activity, 43.4 $\left.\mu \mathrm{mol} /\left(\mathrm{min} / \mathrm{mg}^{-1}\right)\right)$ was resolved into the apoprotein and coenzyme components and reconstituted with $3.8 \mu \mathrm{mol}$ of $2-$ $\left[{ }^{1 .} \mathrm{C}\right] \mathrm{FMN}$ (specific activity, $1.19 \times 10^{5} \mathrm{dpm} / \mu \mathrm{mol}$ ). The original enzyme $(57 \%)$ was reconstituted as judged by binding of $\left[{ }^{14} \mathrm{C}\right] \mathrm{FMN}$. The $\left[{ }^{14} \mathrm{C}\right] \mathrm{FMN}$-lactate oxidase was inactivated anaerobically with a 50-fold excess of DL-2-hydroxy-3-[4$\left.{ }^{3} \mathrm{H}\right]$ butynoate (specific activity, $4.13 \times 10^{5} \mathrm{dpm} / \mu \mathrm{mol}$ ) reduced with $\mathrm{NaBH}_{4}$ and purified by Sephadex G25 chromatography. The ${ }^{14} \mathrm{C} /{ }^{3} \mathrm{H}$ ratio (as $\mathrm{dpm}$ ) in the purified inactivated lactate oxidase was 0.27 . This corresponds to the incorporation of $1.07 \mathrm{~mol}$ of 2 -hydroxy-3-[4- $\left.{ }^{3} \mathrm{H}\right]$ butynoate per mol of bound $\left[{ }^{14} \mathrm{C}\right] \mathrm{FMN}$. Thus, the isoalloxazine ring system must remain intact in the enzyme-bound adduct. However, after release of the adduct from the apoenzyme and purification by

${ }^{2}$ Due to isotope effects of unknown magnitude, the number of atoms of hydrogen incorporated per mole adduct cannot be determined. thin-layer chromatography, the ${ }^{14} \mathrm{C} /{ }^{3} \mathrm{H}$ ratio had decreased to 0.007 . Essentially, all the ${ }^{14} \mathrm{C}$ label has been lost. Thus, on release of the adduct from the enzyme, a structural change occurs such that the pyrimidine ring of the coenzyme is cleaved and $\mathrm{C}-2$ is lost. These results are consistent with the large spectral changes observed on release of the enzyme-bound modified flavin into solution.

In summary, the radioisotope experiments described show that the borohydride stabilized purified adduct contains: (1) hydrogen from $\mathrm{NaBH}_{4}$; (2) at least one nonexchangeable hydrogen from water; (3) the C-4 hydrogen from 2-hydroxy3-butynoate; and (4) the carboxyl carbon of 2-hydroxy-3butynoate. It has lost: (1) the $\alpha$ hydrogen of the inactivator and (2) carbon 2 (at least) of the isoalloxazine ring.

NMR Studies of the Borohydride Stabilized Adduct. A large scale preparation of the borohydride stabilized adduct was undertaken in an effort to obtain further information about its structure by NMR spectroscopy. Two micromoles of lactate oxidase was inactivated anaerobically with DL-2-hydroxy3-butynoate and the adduct was purified by the procedure described in Methods. The Fourier transform NMR spectrum is shown in Figure 5a. The two singlets at $\delta 8.0$ and 8.2 were assigned to the two hydrogens on the benzene ring and were used to determine the relative areas of the other peaks in the spectrum. ${ }^{3}$ The large singlet at $\delta 2.5$, integrating to six protons, corresponds to the $\mathrm{C} 7, \mathrm{C} 8$ methyl groups. The signals due to the hydrogens on the ribitol side chain are probably between $\delta 4.0$ and 4.5 . Peaks observed between $\delta 0$ and 2 were not reproducible and presumably represent contaminants introduced during the purification procedure.

The remaining signals were identified as shown in Figure $5 \mathrm{~A}$ by appropriate isotope substitution. In one experiment inactivated lactate oxidase was reduced with $\left[{ }^{2} \mathrm{H}\right] \mathrm{NaBH}_{4}$ and the flavin-inhibitor adduct was purified according to the standard procedure. The NMR spectrum of the purified adduct differs from Figure $5 \mathrm{~A}$ only in that the singlet integrating to one proton at $\delta 9.2$ is absent. The very high chemical shift of this signal suggests a hydrogen attached to a strongly electron deficient carbon

In a separate experiment, lactate oxidase was inactivated with 2-hydroxy-3-[4- $\left.{ }^{2} \mathrm{H}\right]$ butynoate, reduced with $\mathrm{NaBH}_{4}$ on the enzyme, and the deuterated adduct was purified. The Fourier transform NMR is shown in Figure $5 \mathrm{~B}$. Comparison with Figure $5 \mathrm{~A}$ shows that the doublet at $\delta 7.8$ is now missing and that the doublet at $\delta 7.5$ has coalesced into a singlet. The coupling constant between these two doublets in Figure $5 \mathrm{~A}$ is $4.5 \mathrm{~Hz}$. Thus, the signal at $\delta 7.8$ must be due to the $C 4$ hydrogen of 2-hydroxy-3-butynoate and the signal at $\delta 7.5$ must be due to a hydrogen on an adjacent carbon atom, most probably on C3 of 2-hydroxy-3-butynoate. This hydrogen on C3 presumably comes from water and accounts for the previously discussed observation that at least one nonexchangeable tritium is incorporated into the adduct when the inactivation reaction is carried out in ${ }^{3} \mathrm{H}_{2} \mathrm{O}$. Since each of these hydrogens gives rise to a doublet, they must be isolated from other hydrogens in the molecule. The chemical shifts suggest either aromatic hydrogens or olefinic hydrogens attached to a highly electron-deficient group. Furthermore, since these two hydrogens give rise to signals very close together, they must be in very similar chemical environments. The low value of the coupling constant between the two doublets in the NMR spectrum of the adduct $(J=4.5 \mathrm{~Hz})$ suggests that this group

\footnotetext{
${ }^{3}$ The numbering system for flavins will continue to be followed even
} though the isoalloxazine ring is no longer intact in the adduct. 


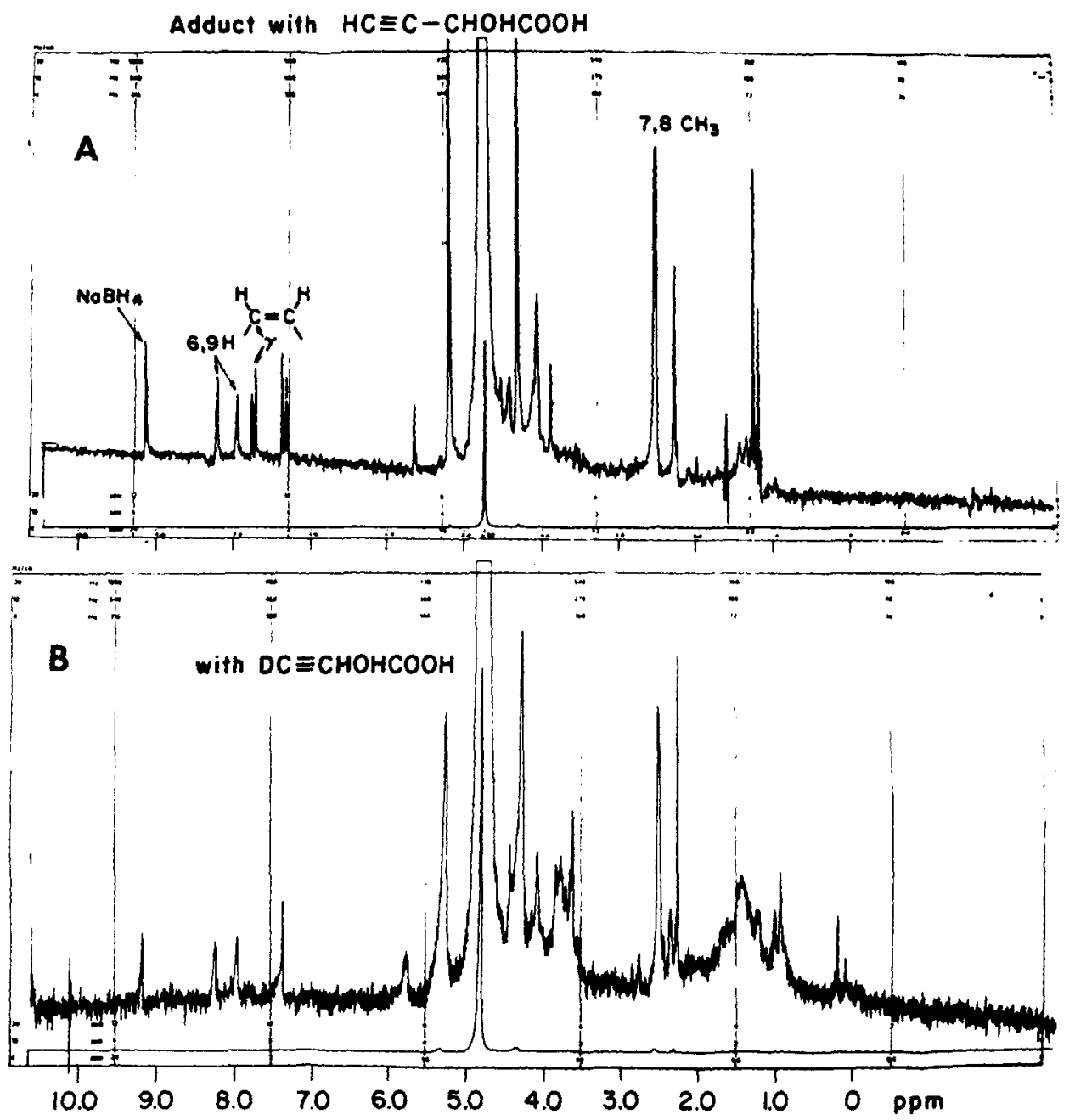

FIGURE 5: (A) Fourier transform NMR spectrum of the flavin adduct isolated from 2-hydroxy-3-butynoate-inactivated, $\mathrm{NaBH}_{4}$-reduced lactate oxidase. The peak at $\delta 9.2$ (labeled $\mathrm{NaBH}_{4}$ ) is assigned to the $\mathrm{H}$ introduced by $\mathrm{NaBH}_{4}$ reduction of the enzyme bound complex (see text). (B) Fourier transform NMR spectrum of the flavin adduct isolated from 2-hydroxy-3-[4. $\left.{ }^{2} \mathrm{H}\right]$ butynoate inactivated, $\mathrm{NaBH}_{4}$-reduced lactate oxidase.

is part of a five- or six-membered ring, i.e., that there are two points of attachment between the inactivator and the flavin. Based on these results, compounds II and III were considered as possible structures for the isolated borohydride stabilized adduct.<smiles></smiles>

II<smiles></smiles>

III
The positive charge on $\mathrm{N} 10$, which is delocalized over the entire ring system in both structures II and III, explains the fact that the chemical shifts of both the $\mathrm{C} 6$ and $\mathrm{C} 9$ hydrogens and the $\mathrm{C} 7$ and $\mathrm{C} 8$ methyl groups on the benzene ring of the adduct occur unusually far downfield compared with C4a,N5-substituted flavins (Ghisla et al., 1973). Similarly, the positive charge in the conjugated system accounts for the fairly high chemical shifts of the $\beta$ and $\gamma$ hydrogens. The $\beta$ and $\gamma$ hydrogens in both structures are isolated from other hydrogens in the molecule and would give rise to two doublets. The coupling constant between the $\beta$ and $\gamma$ hydrogens will be small since they are part of a five-membered aromatic ring.
The signal due to the imine hydrogen on $\mathrm{ClOa}$ will have a chemical shift in the same region as that due to the hydrogen introduced into the adduct from $\mathrm{NaBH}_{4}$. Both structures II and III lack the pyrimidine ring present in flavins consistent with the observation that carbon 2 of FMN is no longer present in the isolated adduct.

To distinguish between structures II and III, the model compound 5,7,8-trimethylpyrroloquinoxalinium iodide (IV) was synthesized.<smiles>Cc1cc2c(cc1C)[n+](C)cc1cccn12</smiles>

IV

In structure III the $\beta$ and $\gamma$ hydrogens from 2-hydroxy-3butynoate should have chemical shifts similar to $\mathrm{H} 2$ and $\mathrm{H} 1$ of the model, while in structure II they would have signals similar to $\mathrm{H} 2$ and $\mathrm{H} 3$. The chemical shifts of the protons of this model and the isolated adduct are compared in Table III. Structure III is clearly eliminated since in the adduct the $\beta$ and $\gamma$ protons give rise to signals close together as do $\mathrm{H} 3$ and $\mathrm{H} 2$ in the model. Furthermore, the coupling constants for the model have values of $J_{1-2}=2.5 \mathrm{~Hz}$ and $J_{2-3}=4.4 \mathrm{~Hz}$. The 
Table III: Summary of NMR Data for Flavin Inhibitor Adduct and Model Compounds.
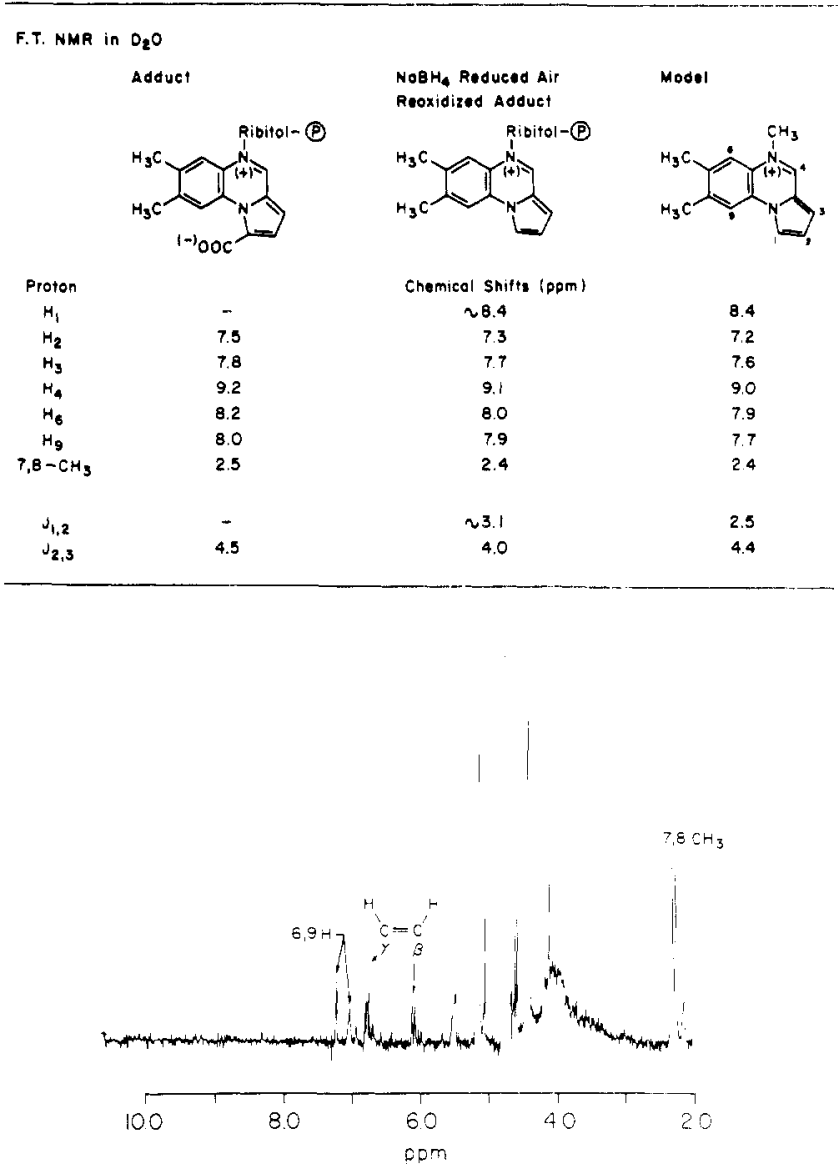

FIGURE 6: Fourier transform NMR spectrum of the sample of Figure $5 \mathrm{~A}, 1 \mathrm{~h}$ after the addition of a few milligrams of solid $\mathrm{NaBH}_{4}$.

coupling constant observed between the $\beta$ and $\gamma$ hydrogens of the adduct, $J=4.5 \mathrm{~Hz}$, is in much better agreement with their assignments in structure II than in structure III. Therefore, synthesis of the model compound IV confirms that the structure of the adduct is II, i.e., the $\alpha$ carbon of the inactivator is attached to N5, not C4a of the flavin.

Chemical Reactivity of the Isolated Flavin Adduct. Since the isolated adduct contains an imine bond, it should react with $\mathrm{NaBH}_{4}$. We found this to be the case. Figure 3 shows the changes in the absorption spectrum of the adduct on addition of excess $\mathrm{NaBH}_{4}$. The absorption maximum at $370 \mathrm{~nm}$ disappears instantaneously as does the fluorescence of the adduct. To identify the product, the NMR spectrum of the adduct was taken immediately after reduction by borohydride (see Figure 6). Absorption by $\mathrm{NaBH}_{4}$ obscured all peaks with chemical shifts less than $\delta 2$. The NMR spectrum obtained is less clear than those discussed above probably due to the formation of some minor side products in the reaction. However, it is clear that there is no signal corresponding to a Schiff base hydrogen. Furthermore, all the signals have been shifted upfield significantly. The $\mathrm{C} 6$ and $\mathrm{C} 9$ hydrogens now give singlets at $\delta 7.0$ and 7.2. The signal due to the $\mathrm{C} 7$ and $\mathrm{C} 8$ methyl groups now occurs at $\delta 2.3$ and has been split into a doublet. Such an upfield shift of all signals would be expected on the loss of the positive charge in the conjugated system. The two vinyl protons are still present in the product, giving rise to a doublet at $\delta 6.7$ and a doublet of doublets at $\delta 6.0$. Each of these signals integrates to a single hydrogen. Since one of the original doublets in the

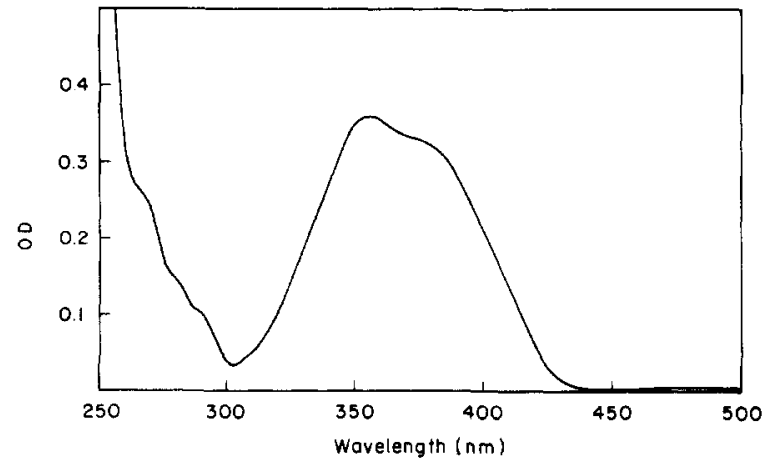

FIGLRE 7: Absorption spectrum of 5,7,8-trimethylpyrroloquinoxalinium iodide in water.

adduct is further split after borohydride reduction, a hydrogen must have been introduced adjacent to either the $\beta$ or $\gamma$ hydrogen.

The product of this second borohydride reduction was found to reoxidize slowly at room temperature in the dark $\left(t_{1 / 2}=\mathrm{ca}\right.$. $24 \mathrm{~h}$ ). Reoxidation results in the return of the absorption band in the $370-\mathrm{nm}$ region (Figure 3 ). Comparison of the absorption spectrum of the product of this reoxidation reaction with that of the model compound, structure IV, shows that they are essentially indistinguishable (cf. Figures 3 and 7). Furthermore, both exhibit strong fluorescence with an emission maximum around $465 \mathrm{~nm}$. The NMR spectrum of the product of this reoxidation, taken 3 days after the borohydride reduction of the purified adduct, is shown in Figure 8 . This spectrum must be interpreted with some caution since by this point the isolated adduct has undergone two chemical reactions without purification of the major product in either case. However, this spectrum closely resembles the NMR spectrum of the turquoise fluorescent adduct before borohydride reduction, as well as that of the model (see Table III). The signal at $\delta 9.2$ is again present, indicating that the $\mathrm{N10}-\mathrm{C} 10 \mathrm{a}$ bond has been reoxidized. The doublet originally at $\delta 7.5$, due to the proton on the $\beta$ carbon of the inactivator, has been shifted to $\delta 7.3$ and is now a triplet. The coupling constant between the doublet at $\delta 7.8$ and the triplet at $\delta 7.3$ is about $4.0 \mathrm{~Hz}$.

Scheme I shows the sequence of reactions proposed for the borohydride reduction and air reoxidation of the isolated adduct. Borohydride reduction is proposed to occur by 1,6 addition to the pyrroloquinoxaline ring to form structure $V$. Since

Scheme I: Borohydride Reduction and Air Oxidation of Purified Adduct.

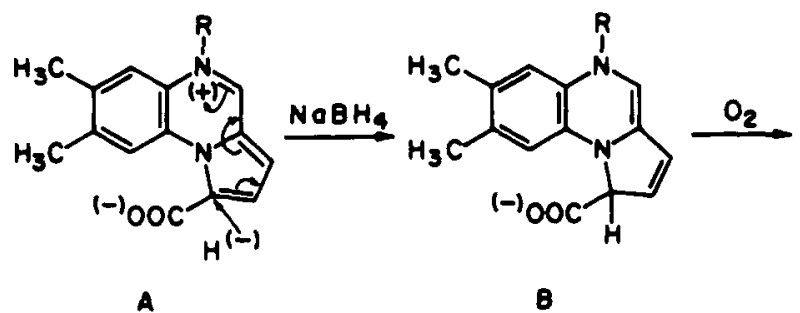
A<smiles></smiles> 


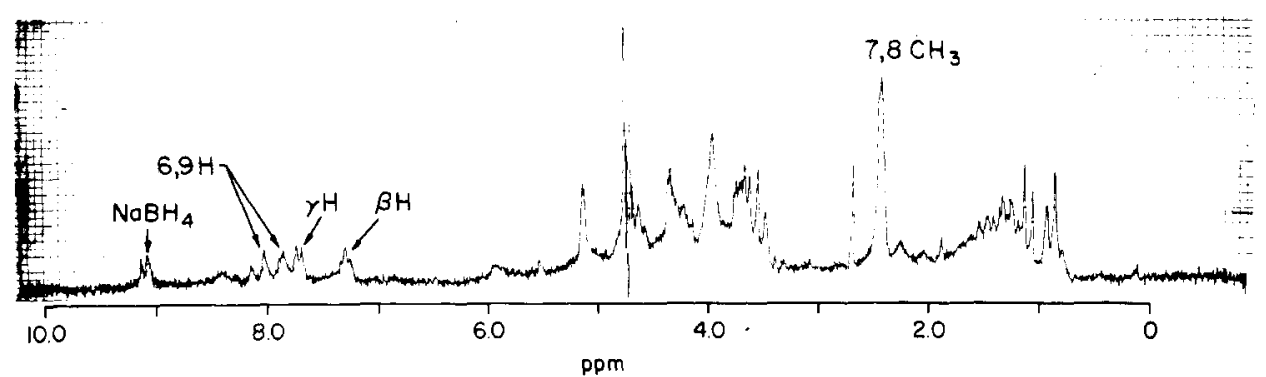

FIGURE 8: Fourier transform NMR spectrum of purified adduct reduced with $\mathrm{NaBH}_{4}$ both on and off the enzyme and allowed to reoxidize in the dark at room temperature for 3 days.

Scheme II: Proposed Reaction Sequence during Isolation of Borohydride Stabilized Adduct.

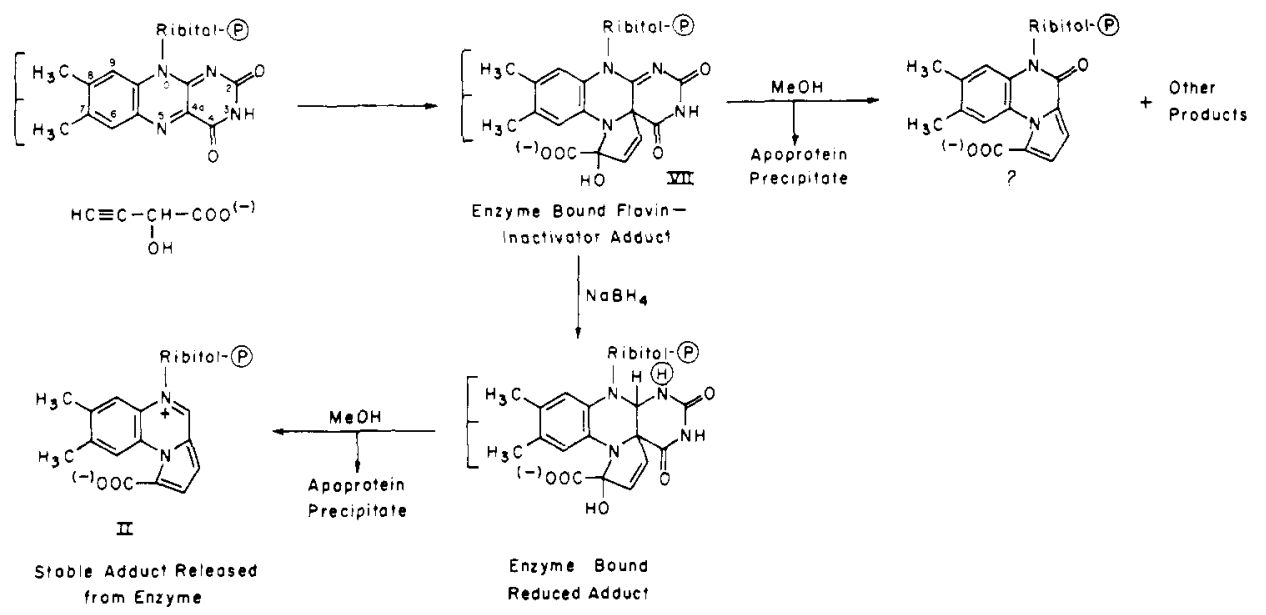

the product is no longer positively charged and the double bond between the $\gamma$ and $\beta$ carbons of the inactivator is no longer conjugated with the rest of the system, the signal due to the $\gamma$ and $\beta$ hydrogens is shifted upfield from the region where aromatic hydrogens appear. Reoxidation is proposed to occur by the same mechanism commonly observed for 1,4-dihydroquinoxalines which are readily oxidized by $\mathrm{O}_{2}$ (Mager and Berends, 1965). In the case of the adduct, the reoxidation reaction is very slow, presumably because the generation of a dication, required as an intermediate, would be very unfavorable. The intermediate dication is proposed to rearrange rapidly by decarboxylation to form the observed product, structure VI. The structure of the reoxidized adduct more closely resembles that of the model than the initially isolated adduct and, in fact, both their chemical shifts (Table III) and their absorption spectra are in better agreement.

To provide further evidence for this proposed sequence of reactions, adduct made with 2 -hydroxy-3-[1-14 C $]$ butynoate was chromatographed on silica gel TLC plates after reoxidation. There was no ${ }^{14} \mathrm{C}$ associated with the major fluorescent species. This confirms that in the reoxidized adduct the $\alpha$ carboxyl of 2-hydroxy-3-butynoate has been lost. Although the adduct was stored for about a week after reoxidation had occurred before thin-layer chromatography, it is unlikely that loss of ${ }^{14} \mathrm{C}$ was due to decomposition since the absorption spectrum of the reoxidized adduct did not change significantly during this time.

Substitution of a hydrogen for the $\alpha$-carboxyl of the inactivator portion of the adduct can account for the change in the splitting of the signal due to the $\beta$ proton from a doublet to a triplet (collapsed quartet). By comparison with the NMR of the model (structure IV), the signal due to the $\alpha$ proton should occur at about $\delta 8.5$. A diffuse peak can be seen in the NMR spectrum of the reoxidized adduct at $\delta 8.4$.
Although the model compound is also instantaneously reduced with excess $\mathrm{NaBH}_{4}$, reduction occurs mainly by addition at the N10-C10a bond, presumably due to lack of a carboxyl group.

\section{Discussion}

The results presented provide evidence that structure II is the structure for the borohydride stabilized adduct released from lactate oxidase after inactivation with 2-hydroxy-3butynoate. Scheme II shows the sequence of reactions postulated to occur in the formation and subsequent isolation of this adduct. The structure of the initial adduct formed on the enzyme is proposed to be a 4a,5-disubstituted 4a,5-dihydroflavin in which the $\gamma$ carbon of the inactivator has added to the $\mathrm{C} 4 \mathrm{a}$ position of the flavin and the $\alpha$ carbon has interacted with N5 (structure VII, Scheme II). The structure of the adduct initially formed is suggested primarily by the structure of the compound finally isolated (structure II). There is additional spectroscopic evidence which supports the proposed structure. The spectrum of the initially formed enzyme-bound adduct before borohydride reduction is characteristic of a 4a,5-dihydroflavin, and the spectral changes observed upon borohydride reduction of inactivated lactate oxidase indicate that reduction occurs at C10a-N1 (Dudley and Hemmerich, 1967). Furthermore, the spectrum of 4a,5-propano-4a,5-dihydro-FMN bound to apolactate oxidase is remarkably similar to the enzyme-bound adduct and borohydride reduction of this complex also occurs at C10a-N1 (Ghisla et al., 1976; Ghisla et al., 1975). Also, Hemmerich et al. have synthesized and studied the reactivity of compound A (Scheme III; Zeller at al., 1972; Gartner, 1974) which is very similar to the proposed structure of the enzyme-bound adduct. They showed that compound $A$ (Scheme III) has spectral properties similar to those of the initial flavin-inhibitor complex. This compound is highly un- 
Scheme III: Decomposition Products of a Flavin Adduct Formed Photochemically from 3-Methyllumiflavin and

$N, N$-Dimethylpropargylamine (Zeller et al., 1972; Gartner, 1974).<smiles>Cc1cc2c(cc1C)N1C(O)C=CC13C(=O)N(C)C(=O)N=C2N3C</smiles>

A<smiles>CNC(=O)NC1c2cccn2-c2cc(C)c(C)cc2N1C</smiles>

B<smiles>Cc1cc2c(cc1C)n1cccc1c(=O)n2C</smiles>

C

stable in water and decomposed to give a mixture of products including those shown in Scheme III. These results are consistent with the observed instability of the adduct initially formed on inactivation of lactate oxidase with 2-hydroxy-3butynoate. Furthermore, we observed that, when the initially formed adduct is released from the enzyme by $\mathrm{MeOH}$, and the products are purified on Bio-Gel P2, the absorption spectrum of one of the species isolated was very similar to that of compound C (Scheme III). Therefore, the formation of this compound is indicated in Scheme II to occur when the initially formed adduct is released from the enzyme without prior reduction with $\mathrm{NaBH}_{4}$.

The flavin-inactivator adduct can be envisaged to be formed by one of several mechanisms. It is unlikely that an allene of 2-hydroxy-3-butynoate, formed by rearrangement after $\alpha$ proton abstraction, is an intermediate, as in the case of inactivation of $\beta$-hydroxydecanoyl thioester dehydrase by an acetylenic substrate analogue (Bloch, 1969). Nucleophilic attack on an allene intermediate would occur on $\mathrm{C} 3$ of the inactivator, not at $\mathrm{C}_{2}$ and $\mathrm{C}_{4}$, the observed attachment sites. However, one possible mechanism for adduct formation involves formation of an allene anion which initiates nucleophilic attack at $\mathrm{C} 4 \mathrm{a}$ of the flavin ring (Scheme IV). Alternatively, an allene radical may initiate attack on the flavin semiquinone formed after partial oxidation of the inactivator had occurred. No evidence has been presented to date to show the involvement of radical intermediates in this enzyme or similar flavoprotein oxidases; however, small concentrations of interacting radical pairs might escape detection.

It is also possible that 2-hydroxy-3-butynoate is first oxidized on the enzyme to the keto acid. $\alpha$-Ketobutynoate may react with the reduced flavin by Michael addition to an $\alpha, \beta$-unsaturated system (Scheme V). A reduced flavin species is formed during the reaction of 2-hydroxy-3-butynoate with lactate oxidase indicating that this mechanism is possible (Ghisla et
Scheme IV: Adduct Formation from Oxidized FMN and 2-Hydroxy-3-butynoic Acid.<smiles>[R]N1C2=N[C@@H](O)NC(=O)C2=Nc2cc(C)c(C)cc21</smiles><smiles>[R]n1c2nc(=O)[nH]c(=O)c-2nc2cc(C)c(C)cc21</smiles><smiles>CCCCCCC</smiles><smiles>[R]N1C2=NC(=O)NC(=O)C2(CC=C=C(O)C(=O)O)Nc2cc(C)c(C)cc21</smiles>

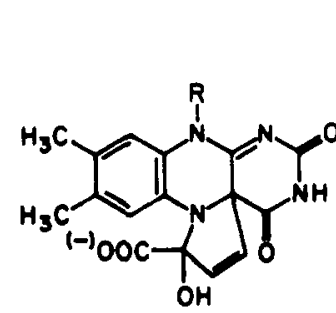

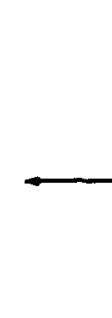

Scheme V: Adduct Formation from Reduced FMN and 2-Keto-3-butynoic Acid.<smiles>[R]n1c2nc(=O)[nH]c(=O)c-2nc2cc(C)c(C)cc21</smiles>

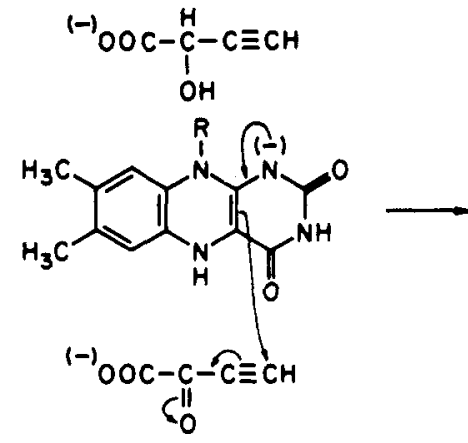<smiles>[R]N1C2=N[C@@H](O)N[C@H](O)[C@]2(CCCCC(=O)O)Nc2cc(C)c(C)cc21</smiles>

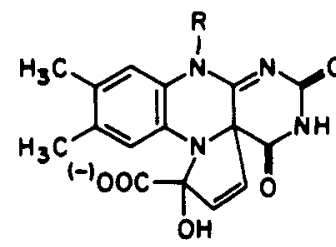<smiles>[Y]N1C2=N[C@@H](O)N[C@H](O)[C@]2(CC[C@H](O)C(=O)O[Na])Nc2cc(C)c(C)cc21</smiles>

al., 1976). The basic distinction between the two mechanisms is that, in one case (Scheme IV), inactivation occurs prior to complete reduction while, in the other case (Scheme V), after 
reduction of the flavin. Since $E_{o x}-S$ and $E_{\text {red }}-P$ are in equilibrium, it is difficult to distinguish between the two alternatives by kinetic measurements. However, vinylglycolic acid, which is oxidized to 2-keto-3-butenoic acid by lactate oxidase (Walsh et al., 1972a), could undergo a Michael addition analogous to 2-keto-3-butynoic acid. This enzyme, as well as six other flavoenzymes (Walsh et al., 1972b; Cromartie and Walsh, 1975; Jewess et al., 1975) which are all inactivated by 2-hydroxy-3-butynoate, are not inactivated by addition of the flavin coenzyme to vinylglycolic acid. These observations tend to argue against the mechanism of Scheme V, but certainly cannot exclude it rigorously.

Regardless of the mechanism by which the adduct is formed, however, its structure provides information concerning the orientation of the inhibitor on the enzyme. Thus, the structure of the flavin-inhibitor adduct shows that the $\alpha$ carbon of the substrate must be located near N5 and not C4a of the isoalloxazine ring during the enzyme-catalyzed oxidation, and the introduction of electrons into the flavin ring probably occurs through N5. The proposal that interaction between substrate and flavin occurs at $\mathrm{N} 5$ is consistent with results obtained with lactate oxidase reconstituted with the coenzyme analogue deaza-FMN (Averill et al., 1975) as well as the experiments which showed that nitroethane anion forms an N5 adduct with the flavin coenzyme of D-amino-acid oxidase (Porter et al., 1973). The isolation of an adduct between 2-hydroxy-3butynoate and lactate oxidase does not necessarily imply that a covalent adduct is formed as an intermediate in the oxidation reaction with normal substrates.

It is particularly noteworthy that the structure of the adduct formed on lactate oxidase with 2-hydroxy-3-butynoate is different from the adduct formed on the flavin enzyme, monoamine oxidase with $N, N$-dimethylpropargylamine (Maycock et al, 1976). In the latter, the terminal carbon of the inactivator is attached to N5. This observation implies that the substrates for these two enzymes are not situated in the same position relative to the flavin coenzyme. Thus, it is possible that $\alpha$-hydroxy and $\alpha$-amino-acid oxidases function by a different mechanism than amine oxidases. This may occur because $\alpha$ proton abstraction and formation of an $\alpha$ carbanion are far more favorable for $\alpha$-hydroxy and $\alpha$-amino acids than for primary amines. In fact, elimination reactions with $\beta$-chloro substrates, indicative of transient carbanion formation, have to date been observed to be catalyzed only by flavoenzymes which use $\alpha$-hydroxy and $\alpha$-amino acids as substrates. No evidence for elimination reactions could be obtained with mitochondrial amine oxidase (Neumann and Abeles, unpublished observations).

\section{Acknowledgments}

We thank Dr. Alfred G. Redfield for putting his excellent NMR facilities at our disposal and for his instruction on their use. We thank Mr. Jed Fisher for preparation of $\left[2-{ }^{14} \mathrm{C}\right] \mathrm{FMN}$.
References

Averill, B. A., Schonbrunn, A., Abeles, R. H., Weinstock, L. T., Cheng, C. C., Fisher, J., Spencer, R., and Walsh, C. T. (1975), J. Biol. Chem. 250, 1603-1605.

Bloch, K. (1969), Acc. Chem. Res. 2, 193-202.

Cheeseman, G. W. H., and Tuck, B. (1966), J. Chem. Soc. C. 852-855.

Choong, Y. S., Shepherd, M. G., and Sullivan, P. A. (1975), Biochem. J. 145, 37-45.

Cromartie, T. H., and Walsh, C. T. (1975), Biochemistry 14, 3482-3490.

Dudley, K. H., and Hemmerich, P. (1967), J. Org. Chem. 32, 3049-3054.

Gartner, B. (1974), Ph.D. Thesis, University of Konstanz, West Germany.

Ghisla, S., Hartmann, U., Hemmerich, P., and Muller, F. (1973), Justus Liebigs Ann. Chem., 1388-1415.

Ghisla, S., Massey, V., Lhoste, J. M., and Mayhew, S. G. (1974), Biochemistry 13, 589-597.

Ghisla, S., Ogata, H., Massey, V., Schonbrunn, A., Abeles, R. H., and Walsh, C. T. (1975), in Flavins and Flavoproteins, Singer, T. P., Ed., Amsterdam, Elsevier, Biochemica et Biophysica Acta Library.

Ghisla, S., Ogata, H., Massey, V., Schonbrunn, A., Abeles, R. H., and Walsh, C. T. (1976), Biochemistry, preceding paper in this issue.

Jewess, P. J., Kerr, M. W., and Whitaker, D. P. (1975), FEBS Lett. 53, 292-296.

Leonard, N. J., Ed. (1956), Org. Synth. 36, 3-6.

Lowry, O. H., Rosebrough, N. J., Farr, A. L., Randall, R. J. (1951), J. Biol. Chem. 193, 265-275.

Mager, H. I. X., and Berends, W. (1965), Recl. Trav. Chim. Pays-Bas 84, 1329-1343.

Maycock, A. L., Abeles, R. H., Salach, J. I., and Singer, T. P. (1976), Biochemistry 15, 114.

McCormick, D. B. (1971), Methods Enzymol. 18B, 544.

Neumann, R., and Abeles, R. H., unpublished observations.

Porter, D. J. T., Voet, J. G., and Bright, H. J. (1973), J. Biol. Chem. 248, 4400-4416.

Redfield, A. G., and Gupta, R. K. (1971), Adv. Magn. Reson. $5,81-115$.

Schonbrunn, A., Walsh, C. T., Ghisla, S., Ogata, H., Massey, V., and Abeles, R. H. (1976), in Flavins and Flavoproteins, Singer, T. P., Ed., Amsterdam, Elsevier (in press).

Sullivan, P. (1968), Biochem. J. 110, 363-371.

Varner, J. E. (1957), Methods Enzymol. 3, 397.

Verny, M., and Vessiere, R. (1967), Bull. Soc. Chim. Fr., 2210-2216.

Walsh, C. T., Abeles, R. H., and Kaback, H. R. (1972b), J. Biol. Chem. 247, 7858-7863.

Walsh, C. T., Schonbrunn, A., Lockridge, O., Massey, V., and Abeles, R. H. (1972a), J. Biol. Chem. 247, 6004-6006.

Zeller, E. A., Gartner, B., and Hemmerich, P. (1972), Z. Naturforsch B 27, 1050-1052. 